\title{
PERFORMANCE AND DURABILITY OF SUSTAINABLE CONCRETE MADE WITH AGGREGATES PRODUCED FROM RETURNED CONCRETE
}

\author{
Giorgio Ferrari $^{1}$, Mitsuya Miyamoto ${ }^{2}$, Alberto Ferrari ${ }^{3}$, Kenichi Yoda $^{4}$, Michele Secco $^{5}$ \\ ${ }^{1}$ Mapei S.p.A.,Milano, Italy \\ ${ }^{2}$ Nagaoka Ready-mixed Company, Izunokuni City, Japan \\ ${ }^{3}$ Nagaoka Ready-mixed Company, Izunokuni City, Japan \\ ${ }^{4}$ Yodagiichi-shoten, Yokohama, Japan \\ ${ }^{5}$ Department of Geosciences, University of Padua, Padua, Italy
}

\begin{abstract}
Concrete is the second most used material in the world, after water. More than 10,000 million cubic meters are globally produced every year, with the consumption of more than 19,000 million tons of natural aggregates (coarse aggregates and sand). About 200 million cubic meters of concrete ( 2 per cent of the global production) are not placed at the jobsite and are returned to readymixed plant where, in most cases, are disposed as waste material. Recently, a new technology to treat returned concrete has been developed. By the new technology, one cubic meter of returned concrete is transformed into 2.3 tons of aggregates, without any waste production. New concrete materials, made by $100 \%$ aggregates produced with the new technology, have been developed in Japan and used in many construction sites. In the present paper, the aggregate production process from returned concrete is reviewed, the composition and design of the new concrete materials are discussed and the mechanical performance and durability tests of the new concrete are presented. These new concrete materials represents an important contribution to concrete sustainability, in terms of natural resources protection, waste disposal and economical benefit both for the ready-mixed plant and the general contractor.
\end{abstract}

Keywords: Aggregates, durability, natural resources protection, recycling, returned concrete, sustainability.

\section{INTRODUCTION}

With an estimated production of 23 billion tons per year, concrete is the most used construction material in the world. Its consumption is over twice the total consumption of all other building materials including wood, steel, plastic and aluminium. Versatility, strength, durability, thermal properties, affordability and abundance of raw materials are the main reasons for its success and represents, at the same time, positive perspectives of sustainability. However, concrete production has several negative impacts on the environment, such as $\mathrm{CO}_{2}$ emissions and the use of nonrenewable natural resources, like natural stone and water, beside the production of waste.

Waste from concrete production mainly consists of returned concrete, the unset concrete that comes back to the plant in the concrete truck as excess material. This can be small amount of concrete leftover at the bottom of the drum, or more significant quantities not used by the costumer at the construction site. Returned concrete at ready-mixed plant is about $5 \%$ of the overall production in the U.S. [1] and $2 \%$ in Japan [2]. In Europe official data are not available, but a rate of $2 \%$ is considered reasonable estimates in Western Europe. No information is presently available for developing countries. Assuming the conservative hypothesis of $1 \%$ the global average rate of returned concrete, it can be estimated that about 230 million tons are globally generated every year, confirming that returned concrete represents a heavy burden for the ready-mixed concrete industry. Current methods of disposing or processing returned concrete include:

- Discharging returned concrete at a location in the ready-mixed plant. The hardened discharged concrete is then removed and stored before dumping. Alternatively, it can be crushed for reuse as base for pavements or fill for other construction.

- Site paving at the ready-mixed production plant and production of concrete elements, such as blocks for breakwaters and counterweights. This possibility is limited by several factors, including the limited area in the plant that can be paved and the local market conditions and opportunities for the elements production.

- Reclamation systems to reuse or dispose the separated ingredients, including the process water with hydration stabilizing admixtures, as needed. The fines and cement materials are washed out of the mix and held as a slurry in suspension tanks. Sand and aggregates are also extracted and stockpiled. The recovered sand and aggregates, together with the slurry water, can be used in the manufacture of new concrete. Such method is 
generally limited to large volume plants in metropolitan areas and require significant capital investments, followed by careful attention to proper practice.

So far, working complexity and capital investments of the current most advanced methods of processing returned concrete, have limited the possibility of achieving high level of recycling and in most countries land filling remains the most used option. In the present paper, a technology for recycling returned concrete, which complies with many requisites of sustainability, is presented.

\section{DESCRIPTION OF THE NEW TECHNOLOGY}

The new method is based on a new two-component powder additive (Part A and Part B) that transforms returned concrete, in few minutes and without the need of specific equipments, into a granular material that can be fully reused as aggregates for new concrete. The new technology permits the complete recycling of returned concrete without the generation of wastes and, through the saving of natural aggregates, the preservation of natural resources. Furthermore, the new technology is very easy to apply and it is not based on toxic substances. Finally, it permits economical benefits through the saving of aggregates and the cut of costs for waste disposal.

Part A and Part B are added in sequence into the drum containing returned concrete. The preferred order of addition depends on the type of cement and must be selected after preliminary tests.

Part A consists of a superabsorbant polymer SAP, based on high molecular weight linear anionic polyacrylamide. Its dosage is in the range 0.4 to $0.8 \mathrm{~kg} / \mathrm{m}^{3}$ of returned concrete, according to $\mathrm{W} / \mathrm{C}$, the type and dosage of cement and climate conditions. When this polymer is added to returned concrete, it causes the sudden increase of viscosity and massive coagulation of the cement paste. By mixing returned concrete in the truck mixer for 2-4 mins, the coagulated cement paste covers the coarse aggregates as a thin layer some millimeters thick and returned concrete is transformed into a granular material consisting of a core formed by the original aggregates covered by a composite material made by cement paste, sand and the superabsorbant polymer, as shown in Figure 1.

Different from crosslinked insoluble polyacrylamide SAPs, which are added to concrete mixtures as internal curing compounds to prevent shrinkage and act as soft aggregates in concrete when filled with water and as air voids when empty [3], SAP of Part A is a linear chain polymer that slowly dissolves during the mixing and its major effect is to increase dramatically the viscosity of the cement paste, without any effect on the porosity of the paste. Once the new aggregates are formed, the SAP remains permanently embedded in the cement matrix and it is no longer active.

Part B is an aluminium compound forming ettringite when added to concrete. The dosage is in the range from 4 to 8 $\mathrm{kg} / \mathrm{m}^{3}$ of returned concrete. The fast formation of ettringite crystals further consumes free water and consolidates, through a sort of "chemical sintering", the fresh granular material, giving enough strength to be further processed. Also the mixing time of Part B is very short, ranging from 2 to 4 minutes. Both Part A and Part B are packed in water soluble plastic bags, quite easy to add through the mouth of the drum and safe to handle.

Independently of the order of addition of Part A and Part B, new method consists of 4 steps:

Step 1 - Addition of the first component (Part A/B) into the drum of the truck mixer containing returned concrete and mixing at full speed for 2-3 minutes.

Step 2 - Addition of the second component (Part A/B) into the drum of the truck mixer containing returned concrete and mixing at medium speed for additional 2-3 minutes.

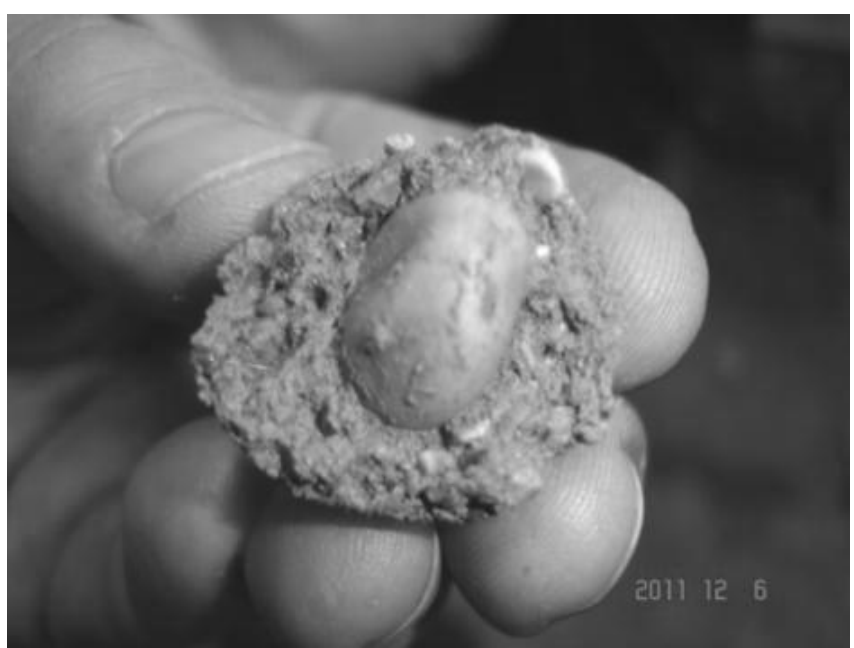

Fig. 1: Fresh granular material after the addition of SAP

Step 3 - Discharge. After Step 2, the granular material is discharged to the ground and stored in a stack, avoiding accumulation in tall piles to prevent excessive pressure over the bottom layers.

Step 4 - Curing. The bulk granular material needs to be cured like any concrete material. The only precaution in this step is to handle the piles with a loader once or twice within the first 24 hours, in order to break the weak bonds of hydrated cement paste among the grains and to separate each other. The optimum time for processing the material depends on many variables, such as the climate conditions, type and dosage of cement and the water to cement ratio. If the granular material is left for longer time before moving, the bonds among the grains become stronger and it is necessary to spend more energy to break the lumps. Once the granular materials have been properly moved, there is no further risk of agglomeration and it can be stored as normal aggregate. In Figure 2, the dependence of optimum processing time on concrete temperature is shown. 


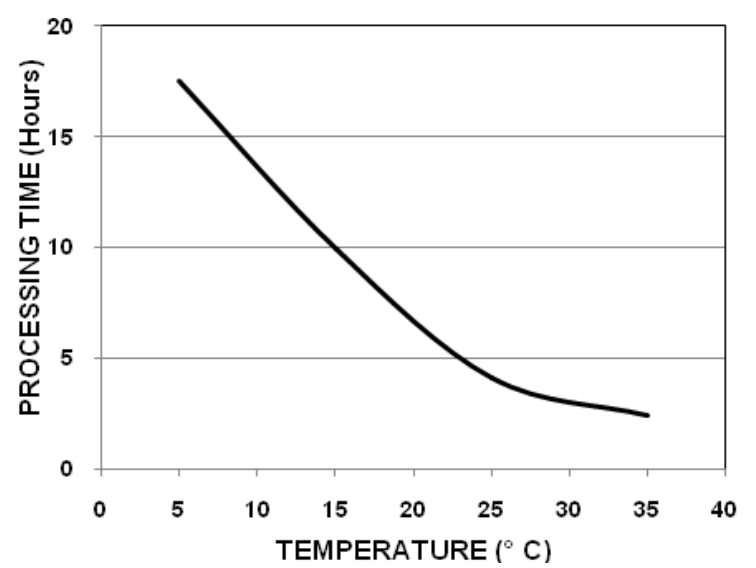

Fig. 2: Relationship between optimum processing time and concrete temperature.

This relationship has been obtained by VCCTL software (Virtual Cement and Concrete Testing Laboratory) developed by NIST (National Institute of Standard and Technology) and gives an idea how climate conditions are important in determining the optimum processing time.

\section{THE NEW AGGREGATES}

The properties of the aggregates obtained with the new technology are related to those of the original aggregates and to the mix-design of the returned concrete (type of sand, cement, admixtures). The composite layer of mortar that surrounds the core of the grains of the new aggregates influences their characteristics, both in terms of size and other physical/chemical properties. Particularly, the presence of the hardened mortar layer covering the coarse aggregates decreases the density and increases the water absorption of the new aggregates. These characteristics are expected to affect both the mass volume and the water demand of new concrete produced with the new aggregates.

In the present work, recycled aggregates were obtained in the laboratory, according the previously described procedure, from a concrete of strength class C25/30 (dosage of 42.5 portland cement $300 \mathrm{~kg} / \mathrm{m}^{3}$, maximum aggregate diameter $30 \mathrm{~mm}, \mathrm{~W} / \mathrm{C}=0.60$ ).

\subsection{General Characteristics of the New Aggregates}

Figure 3 shows the size distribution curves of the aggregates of the original concrete mixture (dotted line) and the aggregates produced with the new process (solid line). The reduction of the fraction finer than $4 \mathrm{~mm}$ for the newly formed aggregates is due to the action of SAP, which agglomerates the finer particles (cement, sand and fillers) around the original aggregates.

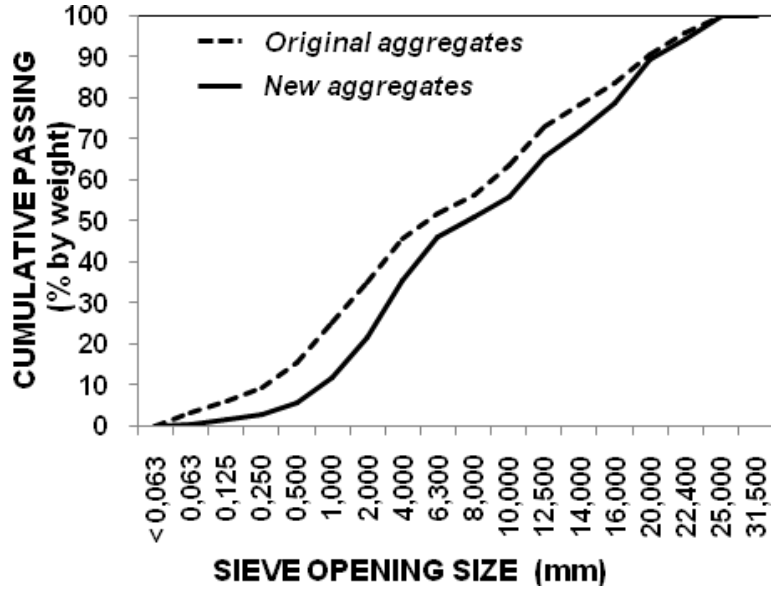

Fig. 3: Size distribution of aggregates from the new process (solid line) and the original ones (dotted line)

The other physical-chemical characteristics of recycled aggregates cured for 28 days are shown in Table 1. The density of the new aggregates is lower than the density of the natural ones (typically higher than $2,600 \mathrm{~kg} / \mathrm{m}^{3}$ ) and it decreases with smaller size. This is due to the relative higher proportion of covering of the smaller aggregates compared to the larger ones.

Table 1: Characteristics of the new aggregates

\begin{tabular}{|l|l|l|l|}
\hline \multirow{2}{*}{ Test } & \multirow{2}{*}{ U.M. } & \multicolumn{3}{|l|}{ New Aggregates Size } \\
\cline { 3 - 4 } & & $\mathbf{L} \mathbf{4 m}$ & $\mathbf{4} \mathbf{~ M m}$ \\
\hline \hline Mass Volume & \multirow{2}{*}{ Kg/M } & 2,350 & 2,450 \\
\hline Water Absorption & $\%$ & 9.7 & 5.3 \\
\hline Soluble Sulphate & $\%$ & 0.38 & 0.44 \\
\hline Soluble Chlorides & $\%$ & 0.011 & 0.021 \\
\hline Organic Substances & - & $\begin{array}{l}\text { Clearer Vs } \\
\text { Ref.Soln }\end{array}$ & $\begin{array}{l}\text { Clearer Vs } \\
\text { Ref.Soln }\end{array}$ \\
\hline
\end{tabular}

For the same reason, water absorption increases with decreasing the size of new aggregates. Regarding the chemical characteristics of the new aggregates, both sulphates and chlorides comply with the limits of European Technical Standard EN 12620:2008 for recycled aggregates ( 0.8 and 0.04 per cent by mass, respectively). The sulphate content in the new aggregates is mainly due to the gypsum of portland cement in returned concrete.

\subsection{Alkali-Silica Reactivity of the New Aggregates}

Alkali-silica reactivity (ASR) of the new aggregates was tested according Italian UNI 8520-22 norm. The new aggregates were crushed and the fraction below $4 \mathrm{~mm}$ was used as sand aggregate to produce two equivalent mortar mixtures with the following composition: 1 part of cement CEMI $42.5 \mathrm{R}$ (1.08\% of alkali equivalent), 2.25 parts of crushed sand and $\mathrm{W} / \mathrm{C}=0.47$. Three mortar specimens equipped with pins were casted for each mixture and cured for 24 hours in normal conditions $\left(20^{\circ} \mathrm{C}, 95 \%\right.$ r.h. $)$. After the initial length measurement, the specimens were cured at 
$38{ }^{\circ} \mathrm{C}, 95 \%$ r.h. for the long term expansion test and length measurements were performed after 12, 30, 60 and 90 days of curing. The average expansion of all the specimens was far below the limit of $0.05 \%$ stated by the norm, as shown in Figure 4, confirming that the new aggregates are not sensitive to ASR.

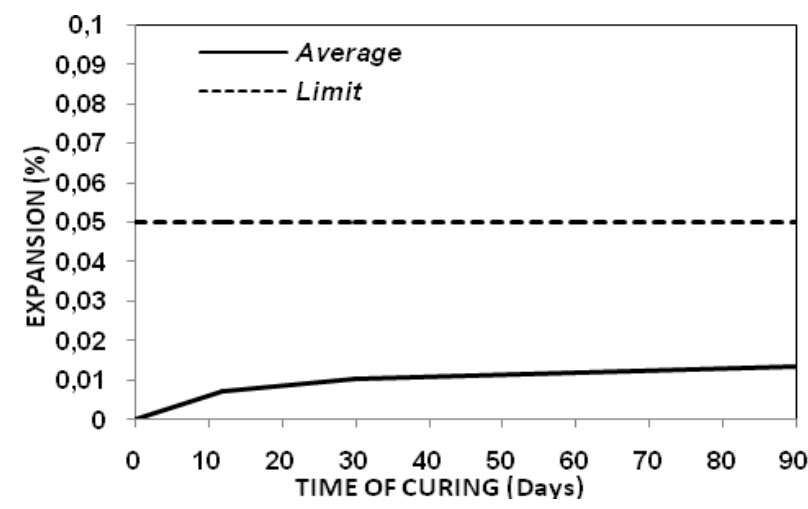

Fig. 4: Average expansion of mortar specimens containing the crushed new aggregate (solid line) compared with the limit of UNI 8520 Italian norm (dotted line)

\section{SUSTAINABILITY ISSUES OF THE NEW TECHNOLOGY}

\subsection{Environmental Issues}

In order to assess the environmental impacts of the new technology, life cycle assessment methodology has been applied to the following framework of ready-mixed production process, including a) production/extraction of raw materials (cement, sand, gravel, water), b) transportation of raw materials to the ready-mixed plant, c) batching of fresh concrete, d) transportation of fresh concrete to the jobsite, e) placing of concrete, f) transportation of returned concrete back to the ready-mixed plant, g) transformation of returned concrete into aggregates and recycle to produce new ready-mixed concrete. As a comparison, the same procedure has been applied to the option of dumping returned concrete to landfill (g'). The overall process is shown in the diagram of Figure 5.

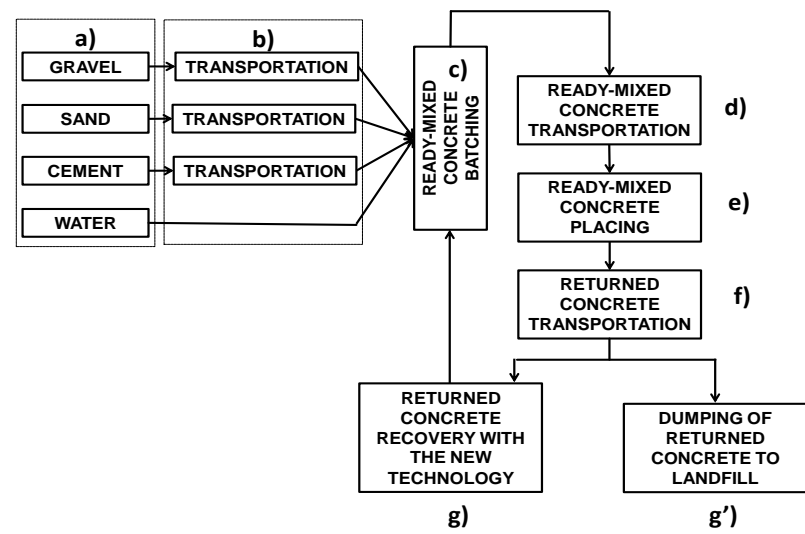

Fig. 5: Diagram of unit raw materials/processes involved in the ready-mixed concrete production, with different options for returned concrete
Commercial GaBi software (PE International, Germany) was used to compare the different scenarios. This software is designed to perform life cycle assessment, life cycle engineering, technology benchmarking/system analysis, energy efficiency analysis and sustainability reporting. The software is built on GaBi LCA database, integrated with the Swiss Ecoinvent database. The mix-design of the readymixed concrete used for the LCA is reported in the following Table 2 .

Table 2: Mix-design of ready-mixed concrete used for the comparison of LCA

\begin{tabular}{|l|l|}
\hline Ingredient & Dosage $\mathbf{( k g / \mathbf { m } ^ { 3 } )}$ \\
\hline \hline Portland cement & 300 \\
\hline Coarse aggregate $(5-30 \mathrm{~mm})$ & 950 \\
\hline Sand $(0-5 \mathrm{~mm})$ & 800 \\
\hline Water & 190 \\
\hline
\end{tabular}

Admixtures, like plasticizers and superplasticizers, were not considered in the LCA of concrete production because, according to the literature, their impact is low compared to the other ingredients (Cement Admixtures Association, 2006). For transportation, an average distance of $100 \mathrm{~km}$ was estimated for raw materials, $30 \mathrm{~km}$ to transport fresh concrete from the RMC plant to the jobsite and $30 \mathrm{~km}$ to transport concrete waste from RMC plant to landfill. Unit environmental impacts of returned concrete recovered with the new technology (step g in Fig. 5) and dumped to landfill (step g' in Fig. 5) were calculated on the basis of $1000 \mathrm{~m}^{3}$ of concrete production and under the hypothesis of a rate of $2 \%$ of returned concrete. The impacts on returned concrete treated with the different options are reported in the following Table 3 .

Table 3: Environmental impacts per cubic meter of returned concrete in the hypothesis of $\mathrm{g}$ ) recovery with the new technology and g') dumping to landfill.

\begin{tabular}{|l|l|l|l|}
\hline \multirow{2}{*}{ Impact parameter } & \multirow{2}{*}{ u.m. } & \multicolumn{2}{|c|}{$\begin{array}{l}\text { Impact/m } \\
\text { returned concrete }\end{array}$} \\
\cline { 3 - 4 } & & g) & g') \\
\hline \hline $\begin{array}{l}\text { Global Warming } \\
\text { Potential (GWP } 100)\end{array}$ & $\mathrm{kg} \mathrm{CO}$ eq. & 3.26 & 268 \\
\hline $\begin{array}{l}\text { Eutrophication } \\
\text { Potential (EP) }\end{array}$ & $\begin{array}{l}\mathrm{kg} \mathrm{PO} \mathrm{PO}_{4}^{3-} \\
\text { eq. }\end{array}$ & 0.0094 & 0.19 \\
\hline $\begin{array}{l}\text { Acidification Potential } \\
\text { (AP) }\end{array}$ & $\mathrm{kg}$ of S eq. & 0.0644 & 0.864 \\
\hline $\begin{array}{l}\text { Ozone layer Depletion } \\
\text { Potential (ODP) }\end{array}$ & $\begin{array}{l}\mathrm{kg} \mathrm{CFC-11} \\
\text { eq. }\end{array}$ & $\begin{array}{l}2.35 \mathrm{E}- \\
07\end{array}$ & $\begin{array}{l}2.75 \mathrm{E}- \\
08\end{array}$ \\
\hline $\begin{array}{l}\text { Depletion of abiotic } \\
\text { resources - elements } \\
\text { (ADP elements) }\end{array}$ & $\mathrm{kg} \mathrm{Sb} \mathrm{eq.}$ & $\begin{array}{l}8.97 \mathrm{E}- \\
06\end{array}$ & $\begin{array}{l}1.79 \mathrm{E}- \\
05\end{array}$ \\
\hline $\begin{array}{l}\text { Depletion of abiotic } \\
\text { resources - fossil fuel } \\
\text { (ADP fossil fuel) }\end{array}$ & $\mathrm{MJ}$ & 109 & 2360 \\
\hline
\end{tabular}

From Table 3, it is evident the lower impact, for most parameters, of the new technology to recover returned concrete compared to the dumping option. The reasons for this reduction must be ascribed to the following factors: 
- Impact of transportation of returned concrete from the RMC plant to the landfill. After hardening at RMC plant, returned concrete must be transported to landfill by truck, with consequent consumption of fuel and emissions. On the other side, with the new technology, returned concrete is processed and fully reused at the RMC plant and the truck mixer and the loader are engaged only for few minutes.

- Use of landfill. Dumping of returned concrete contributes to landfill impacts, such as the land use, gas emissions and groundwater contamination. Particularly, concrete debris can leach hexavalent chromium to groundwater. The new technology does not produce any waste and the returned concrete is fully recycled for the production of new concrete.

- The only negative contribution originates from the additive, with a slight increase of ODP $\left(235 \mu \mathrm{g} / \mathrm{m}^{3}\right.$ of returned concrete, compared to $28 \mu \mathrm{g} / \mathrm{m}^{3}$ for the dumping option).

Another advantage of the new technology is the saving of virgin aggregates. By transforming returned concrete into aggregates that can be used to produce new concrete at the RMC plant, the new technology allows to reduce the consumption of natural aggregates and, therefore, to further reduce the impact on the environment. Assuming a volume of returned concrete of $2 \%$ of the total concrete production, about $5 \%$ of coarse natural aggregate fraction can be replaced with the new ones. On the other side, no saving is achieved by dumping returned concrete. The resulting $\mathrm{GWP}_{100}$ is $324 \mathrm{~kg}$ $\mathrm{CO}_{2}$ eq. per cubic meter for the concrete produced with $5 \%$ of the new aggregates and $331 \mathrm{~kg} \mathrm{CO}_{2}$ eq. per cubic meter when returned concrete is dumped. A value of $325 \mathrm{~kg} \mathrm{CO}_{2}$ eq per cubic meter has been calculated in the case of no leftover concrete $(0 \%$ returned concrete).

\subsection{Social Issues}

The new technology is based on non dangerous additives and consequently health risks associated with their use are low. Furthermore, the additives are packed in water soluble bags which minimize the risk of contact for workers. By eliminating the production of concrete waste, the new technology reduce the use of landfill and gives a positive contribution to the use of land for recreation. Finally, the new technology represents a positive contribution for the commitment to reduce greenhouse effect and to a conscious use of energy.

\subsection{Economic Issues}

The main cost of the new technology is represented by the additives. Typically, a dosage of $6.5 \mathrm{~kg}$ of additive is used to treat 1 cubic meter of returned concrete. Minor additional costs are due for the extended service of the truck mixer and the loader. Considering that the new technology allows to cut the costs of dumping returned concrete and to save virgin aggregates, the economic advantage of using the new technology must be evaluated together with the costs associated with the use of landfill and the price of natural aggregates, factors which can differ considerably from country to country. Furthermore, the strictness of environmental laws and fines for illegal dumping by public controllers are important factors which can encourage the use of the new technology. For instance, in Japan the new technology is quickly expanding because the costs associated with dumping of returned concrete are very high (about 17 euro/Ton) and the same is for the price of aggregates (about 19 euro/Ton). Similar conditions apply to Australia, where the costs associated with landfill are not as high as in Japan (about 5 euro/Ton), but the price for aggregates is high (about 17 euro/Ton). Furthermore, Australia has a quite strict environmental law which encourages the adoption of sustainable technologies. In Western Europe, the average costs for dumping is about 10 USD/Ton and the average price for aggregates is around 10 USD/Ton. In such conditions, the new technology is economically advantageous and its rate of diffusion is mainly related to the local environmental regulations and controls. Nevertheless, also in countries where the costs associated with landfilling and the price of aggregates are low (less than 7 euro/Ton), like in UAE, the new technology is going to be applied. In this case, the scarce availability of water and transportation costs are the driving force in favoring the diffusion of the new technology.

\section{CONCRETE WITH THE NEW AGGREGATES}

The aggregates produced with the new technology are currently used in Europe to produce new concrete, according to EN 206:2006, as a partial replacement of the coarse fraction of natural aggregates. This norm allows to use the aggregates recovered from returned concrete to up to 5 per cent over the whole aggregate, without separation of the different fractions. Reuse of higher amount can be accomplished after separation of the different fractions and after verifying the compliance with the EN 12620:2008 norm on aggregates for concrete. It has already been shown that concrete produced with 30 per cent replacement of the new aggregates, without separation of the different fractions, exhibits mechanical strength and durability properties comparable with equivalent concrete produced only with natural aggregates [4].

\subsection{The Development of the New Technology in}

\section{Japan}

Japan is a highly industrialized country in a relatively small area (about 130 million inhabitants in $377,000 \mathrm{~km}^{2}$ ) and Construction \& Demolition Waste C\&DW account for over 77 million Tons/year. For this reason recovery and recycling is highly encouraged by the Government and protocols have been issued for many materials. Japanese Industrial Standards classifies recycled aggregates in three classes: $\mathrm{H}$, $\mathrm{M}$ and L. Class $\mathrm{H}$ recycled aggregate is produced through sophisticated processes, such as grinding, milling and grading, and it is nearly comparable to the quality of natural aggregates. Class $\mathrm{M}$ and $\mathrm{L}$ aggregates are produced through more economic systems and their quality differ from $\mathrm{H}$ type 
in that considerable amount of cement paste and mortar sticks to the surface of the coarse aggregate particle. Aggregates produced with the new technology fully complies with the quality characteristics of Class L aggregates and are covered by JIS A 5023 standard [5]. According to this norm, class $\mathrm{L}$ aggregates can be used to produce ready-mixed concrete for civil engineering construction and building construction with nominal strength and slump of $24 \mathrm{~N} / \mathrm{mm}^{2}$ and $18 \mathrm{~cm}$, respectively [6]. Therefore, the use of aggregates produced with the new technology is limited to plain concrete structures, small reinforced concrete structures, concrete blocks reinforced with steel bars, etc.. Nevertheless, the demand of this type of concrete is remarkable and it can be estimated that about 15 per cent of the concrete placed in big urban areas belongs to this type. New type of concrete, hundred per cent based on aggregates produced with the new technology, has been developed and marketed under different brands, in Japan: Neomix $^{\circledR}$, developed by Yodagiichi-Shouten Sakuragaoka RMC (Yokohama) and Econ ${ }^{\circledR}$, developed by Nagaoka RMC (Izu-no Kuni City). More than 5,000 cubic meters Neomix ${ }^{\circledR}$ and more than 8,000 cubic meters Econ ${ }^{\circledR}$ have been placed since 2013 in the Yokohama-Tokyo and Shizuoka-NagoyaOkayama areas, respectively. Typical applications are shown in the following Figures 6 to 9 .

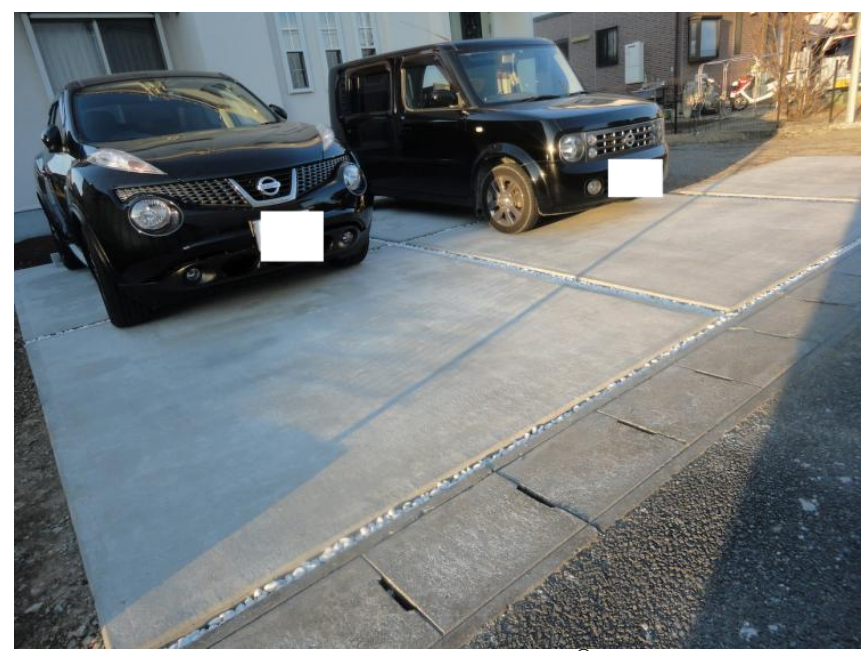

Fig. 6: Parking lot produced with Econ ${ }^{\circledR}$ in Shizuoka area

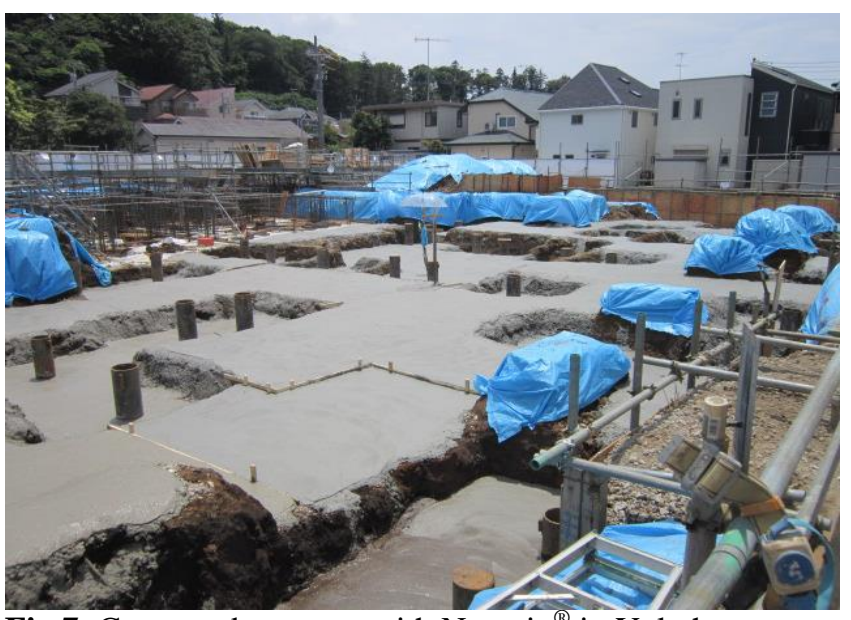

Fig.7: Concrete basement with Neomix ${ }^{\circledR}$ in Yokohama area

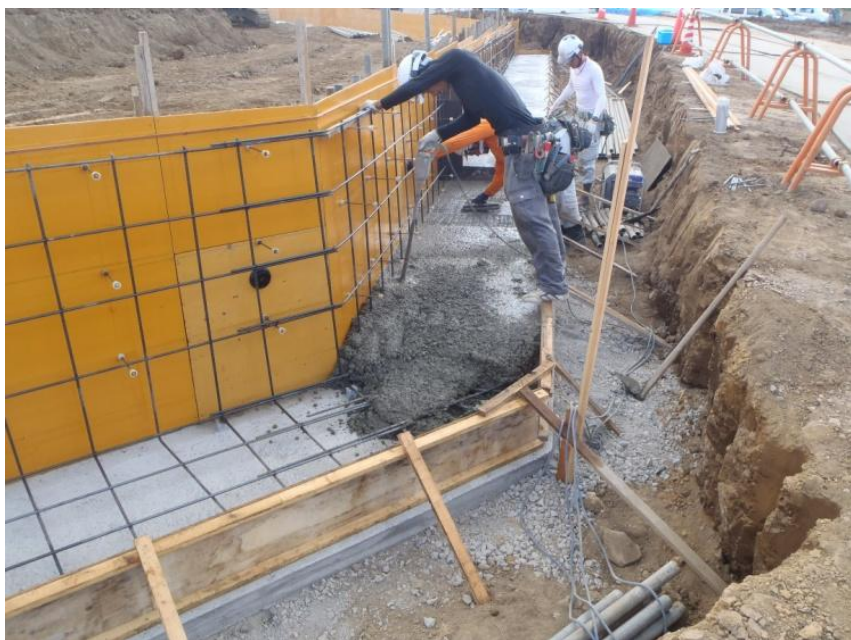

Fig. 8: Placement of Econ ${ }^{\circledR}$ for reinforced wall in Shizuoka area.

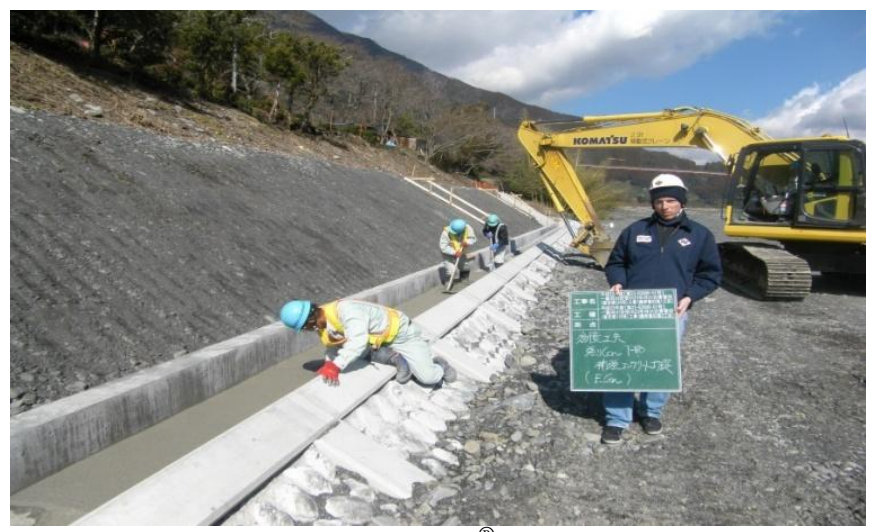

Fig. 9: Placement of Econ ${ }^{\circledR}$ in Shizuoka area.

In the present paper, mechanical performance and durability of concrete produced according to $\mathrm{Neomix}^{\circledR} / \mathrm{Econ}^{\circledR}$ mix design, characterized by the complete replacement of coarse natural aggregates with those produced with the new technology, have been assessed.

\section{EXPERIMENTAL}

Concrete of nominal class C 16/20, according to EN 206-1, were produced in the laboratory, by using aggregates obtained with the new technology from a fresh concrete of nominal class C 20/25 (Mix 1). Equivalent concrete with the same mix-design, but with natural aggregates, was produced as reference and compared in all tests with the new concrete (Mix 2). In order to comply with Japanese standards, in both the concretes an air-entraining agent was introduced to have an air content of 4-5 per cent. The complete mix design and the characteristics of fresh mixtures of both the concretes are shown in Table 4.

Table 4: Composition and characteristics of fresh concrete made with the new aggregates and reference concrete made only with natural aggregates.

\begin{tabular}{|l|l|l|}
\hline Component/Parameter & Mix 1 & Mix 2 \\
\hline \hline Cement IIA-LL 42.5R $\left(\mathrm{kg} / \mathrm{m}^{3}\right)$ & 271 & 271 \\
\hline Water $\left(\mathrm{kg} / \mathrm{m}^{3}\right)$ & 173 & 173 \\
\hline W/C & 0.64 & 0.64 \\
\hline
\end{tabular}




\begin{tabular}{|l|l|l|}
\hline Superplasticizer $\left(\%\right.$ bwc $\left.^{*}\right)$ & 0.4 & 0.8 \\
\hline Air entraining agent $\left(\%\right.$ bwc $\left.^{*}\right)$ & 0.075 & 0.075 \\
\hline Natural sand $\mathrm{S} 1\left(\mathrm{~kg} / \mathrm{m}^{3}\right)$ & 405 & 147 \\
\hline Natural sand $0 / 8 \mathrm{~mm}\left(\mathrm{~kg} / \mathrm{m}^{3}\right)$ & - & 916 \\
\hline Natural aggregates $10 / 20 \mathrm{~mm}\left(\mathrm{~kg} / \mathrm{m}^{3}\right)$ & - & 308 \\
\hline Natural aggregates $20 / 30 \mathrm{~mm}\left(\mathrm{~kg} / \mathrm{m}^{3}\right)$ & - & 477 \\
\hline New aggregates $0 / 5 \mathrm{~mm}\left(\mathrm{~kg} / \mathrm{m}^{3}\right)$ & 420 & - \\
\hline New aggregates $5 / 30 \mathrm{~mm}\left(\mathrm{~kg} / \mathrm{m}^{3}\right)$ & 825 & - \\
\hline Air content $\%$ & 4.6 & 4.6 \\
\hline Density of fresh concrete $\left(\mathrm{kg} / \mathrm{m}^{3}\right)$ & 2157 & 2294 \\
\hline Slump $(\mathrm{cm})$ & 21 & 21 \\
\hline
\end{tabular}

"bwc = by weight of cement

Natural sand S1 was necessary in Mix 1 in order to compensate the lack of fine material of the new aggregates (see Figure 3). It is also interesting to observe the lower density of the fresh concrete mixture produced with the new aggregates (about 6 per cent less than the reference concrete), due to the lower density of the new aggregates compared to the natural ones.

\subsection{Microstructure Analysis of Concrete}

The microstructural and microchemical characteristics of the concretes prepared with both natural (Mix 2) and recycled aggregates (Mix 1) were assessed by means of scanning electron microscopy and energy dispersive X-ray microanalysis (SEM-EDS). Representative concrete portions were stabilized by embedding in epoxy resin and cross-cuts were polished and carbon-coated. A CamScan MX2500 SEM was used for analyses, equipped with $\mathrm{a} \mathrm{LaB}_{6}$ cathode, a four quadrant solid state BSE detector for imaging and a EDAX-EDS energy dispersive $\mathrm{X}$-rays fluorescence spectrometer for microanalysis.

The results highlighted marked differences in the size and features of the interfacial transition zone (ITZ) between hardened cement paste and coarse aggregates. Mix 2 showed a typical ITZ of medium-low strength concretes, with the development of voids at the interface with the coarse aggregate, as may be observed even at the macroscopic level (Figure 10a). By microscopic observation (Figures 10b, 10c), several microstructural features related to wall effect and internal micro-bleeding phenomena, responsible for the ITZ development [7, 8], are quite evident; particularly, a clear enrichment in capillary porosity over a volume of cementitious matrix surrounding the aggregate, with a thickness generally in the range from 30 to $70 \mu \mathrm{m}$ can be recognized. Furthermore, the occurrence of continuous detachment between the aggregate particles and the hardened cement paste is often observable. The ITZ domains are also evident from EDAX-EDS analysis, indicating a calcium-rich phase in contact with the aggregate particles (Figure 10d): such evidence indicates the preferential precipitation of large portlandite crystals in place of the standard interconnected network of hydrated silicate phases, due to a preferential accumulation of water in such portions and consequent nucleation and growth of calcium hydroxide from calcium saturated solutions. Such local change in the mean mineralogical composition is detrimental to the mechanical properties of the cement matrices in the interfacial portions, which are consequently preferential places for the development of local mechanical stresses.

On the other hand, concretes produced with recycled aggregates are characterized by the presence of two distinct interfacial portions, the first between the nucleus of original aggregate and the composite cementitious shell of the recycled aggregate (internal interface) and the second between the recycled aggregate itself and the new concrete matrix (external interface). Even at a macroscopic observation, no evident development of interfacial porosity is detectable at the two interfaces (Figure 11a). The microstructural analysis of the internal interface did not show the typical characteristics of ITZ: the cement matrix is dense and strongly interconnected, similar to the bulk paste of the recycled aggregate, without evidence of increased capillary porosity and detachments (Figure 11b). Similar characteristics are observable also for the external interface (Figure 11c). The homogeneity between the two cement matrices is confirmed by chemical microanalyses (Figure 11d), with stable $\mathrm{Ca} / \mathrm{Si}$ ratios around a mean value without strong peak variations along the interface. Beside the interfacial properties, the cement matrix of recycled aggregates is characterized by the following peculiar features: a) reduced capillary porosity, typical of concretes of higher strength compared to that the original concrete and b) the presence of higher amount of unreacted clinker particles.

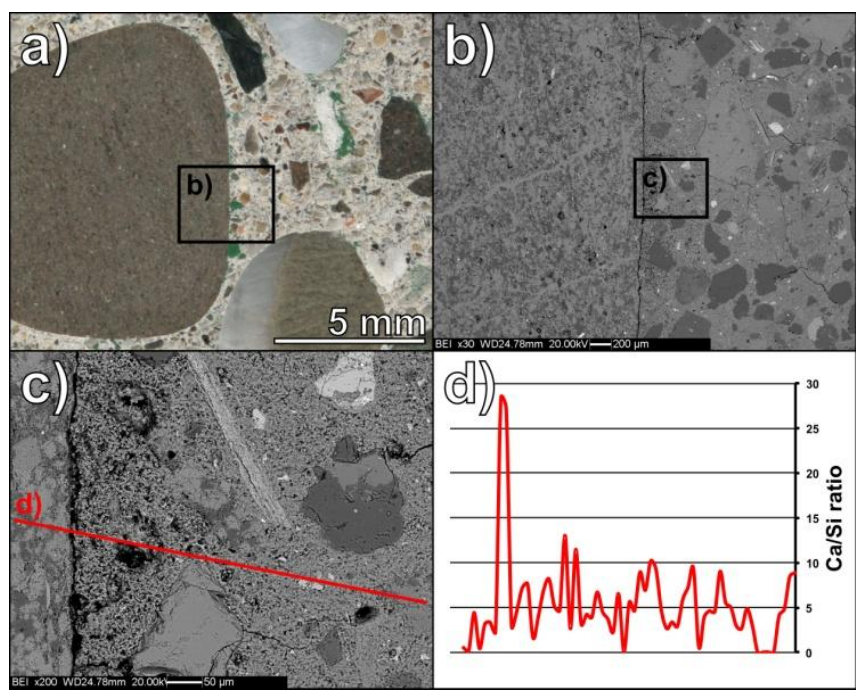

Fig. 10: Microstructural and microchemical analyses of reference concrete. a) macroscopic view of a polished section portion; b) backscattered electron image (BEI) of the area highlighted in a); c) BEI of the area highlighted in b); d) variation of the $\mathrm{Ca} / \mathrm{Si}$ ratio along the line highlighted in $\mathrm{c}$ )

These characteristics seem to be related to the process of production of the new aggregates: the addition of the two additives causes both a strong reduction of the water to cement ratio (promoted by the SAP polymer) and a filler/densification effect (promoted by the aluminum compound), with consequent development of denser 
hardened cement matrices. Such densification is further enhanced by the physical compaction promoted by the process of grains formation inside the truck mixer. At the same time, the reduction of W/C favors the increase of residual unhydrated clinker particles inside the cement matrix, conferring a delayed reactivity to the recycled aggregates and potential "self healing" properties, when reused to produce new concrete. All these features have positive consequences on the characteristics of the interfacial zones. The internal ITZ is drastically reduced, due to both the physical action of the agglomeration process and the improved characteristics of the recycled matrices, typical of high performance concretes (e.g. low internal micro-bleeding). As for the external interface, the absence of ITZ is the result of the capacity of the new aggregates to absorb the water normally accumulated at the interface caused by micro-bleeding and wall effects and to develop, at the same time, a dense network of additional hydrated phases due to the presence of residual reactive clinker particles. Such capacity of refining the ITZ of concrete promoted by the new aggregates may compensates their lower mechanical properties, compared with the original aggregates, and confer adequate mechanical and durability properties to concretes produced with such aggregates.

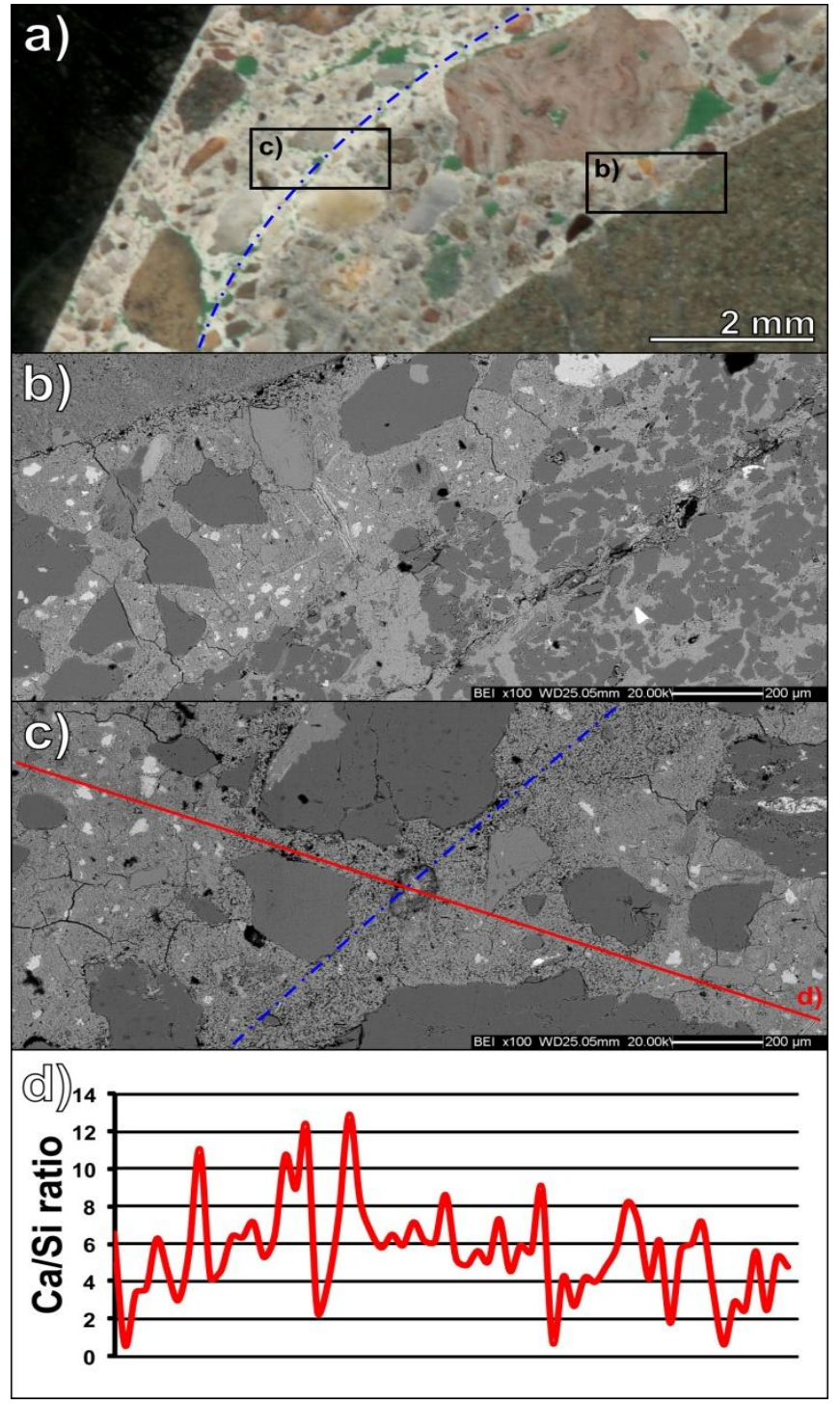

Fig. 11: Microstructural and microchemical analyses of concrete produced with the new aggregates. a) macroscopic view of a polished section portion (interface highlighted by the blue line); b) backscattered electron image (BEI) of the area highlighted in a); c) BEI of the area highlighted in a); d) variation of the $\mathrm{Ca} / \mathrm{Si}$ ratio along the line highlighted in $\mathrm{c}$ ).

\subsection{Compressive Strength}

Compressive strength of concrete produced with the new aggregates (Mix 1) and the reference concrete with natural aggregates (Mix 2) was measured after 1, 7 and 28 days of curing in plastic moulds in normal conditions $\left(20{ }^{\circ} \mathrm{C}\right.$ and $>95 \%$ r.h.) on $15 \times 15 \times 15 \mathrm{~cm}$ cubic specimens. Results are shown in Table 5.

Table 5: Compressive strength of concrete made with the new aggregates (Mix 1) compared with similar concrete with natural aggregates (Mix 2)

\begin{tabular}{|l|l|l|l|l|l|l|}
\hline \multirow{2}{*}{ Sample } & \multicolumn{2}{|l}{$\mathbf{1}$ day } & \multicolumn{2}{c|}{$\mathbf{7}$ days } & \multicolumn{2}{c|}{$\mathbf{2 8}$ days } \\
\cline { 2 - 7 } & $\mathbf{k g} / \mathbf{m}^{\mathbf{3}}$ & $\mathbf{M P a}$ & $\mathbf{~ k g} / \mathbf{m}^{\mathbf{3}}$ & $\mathbf{M P a}$ & $\mathbf{~ k g} / \mathbf{m}^{\mathbf{3}}$ & $\mathbf{M P a}$ \\
\hline \hline Mix 1 & 2140 & 6.9 & 2112 & 19.5 & 2106 & 23.7 \\
\hline Mix 2 & 2290 & 8.0 & 2276 & 23.1 & 2266 & 27.6 \\
\hline
\end{tabular}


Results indicate that concrete produced with the new aggregates (Mix 1) show, at all curing time, only a moderate decrease of compressive strength in comparison with reference concrete produced with natural aggregates (Mix 2 ). The average decrease of strength of about 14 per cent seems to be related to the reduced density of concrete made with the new aggregates (average reduction of about 7 per cent).

\subsection{Water Permeability}

Water permeability was measured on both the concretes produced with the new aggregates (Mix 1) and with the natural ones (Mix 2). Measurements were accomplished according EN-12390-8 test method on $15 \times 15 \times 15$ concrete cubes cured for 28 days. Two cube specimens for each type of concrete were subjected to a water pressure of $500 \mathrm{kPa}$ for 72 hours. This time elapsed, the amount of penetrated water was calculated by the weight of each cubes before and after the test and by measuring the depth of water penetration on vertical sections of the cubes, as shown in the following Figures. 12 and 13. Results are shown in Table 6, as the average of the two cubes for each type of concrete.

Table 6: Water permeability of concrete made with the new aggregates (Mix 1) compared with similar concrete with natural aggregates (Mix 2)

\begin{tabular}{|l|l|l|}
\hline Sample & $\begin{array}{l}\text { Absorption } \\
\text { \% }\end{array}$ & $\begin{array}{l}\text { Max depth of } \\
\text { penetration }(\mathbf{m m})\end{array}$ \\
\hline \hline Mix 1 & 1.14 & 93 \\
\hline Mix 2 & 0.64 & 72 \\
\hline
\end{tabular}

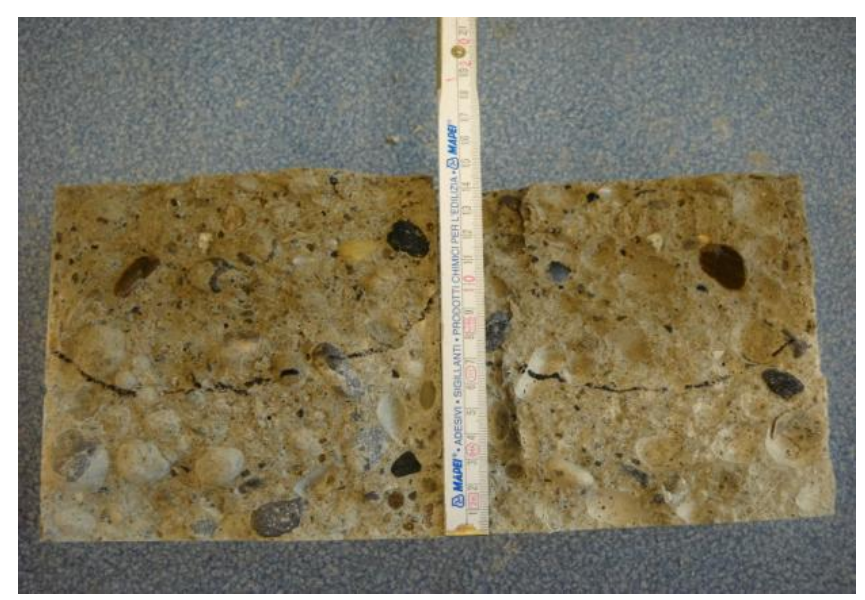

Fig. 12: Water penetration front of concrete cube of Mix 1, produced with the new aggregates.

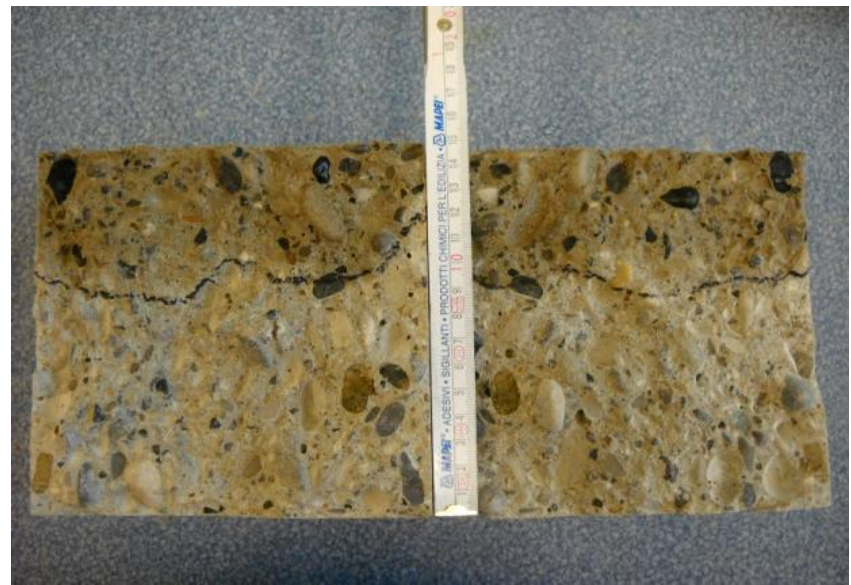

Fig. 13: Water penetration front of concrete cube of Mix 2, produced with natural aggregates.

Results of water penetration indicate that concrete produced with the new aggregates is more permeable to water in comparison with equivalent concrete produced with natural aggregates. These findings differ from the previous ones obtained on concrete produced with only 30 per cent of the new aggregates as replacement to the coarse fraction of natural aggregates. Those results indicated that concrete produced with the new aggregates was less permeable to water compared with that produced with natural aggregates and this was attributed to the better interfacial transition zone (ITZ) between the new aggregates and the cement paste [4]. In the case of $100 \%$ replacement, the higher water absorption of the fine fraction of the new aggregates (Table 1) compensates the benefits of the better ITZ between the coarse fraction of the new aggregates and the cement paste.

\subsection{Freeze/Thaw Resistance}

Measurements of freeze/thaw resistance was determined according EN-12390-9 test method. Cubic specimens $15 \times 15 \times 15 \mathrm{~cm}$ of both concrete produced with the new aggregates (Mix 1) and with natural aggregates (Mix 2) were cured for 28 days in normal conditions. Horizontal sections of each specimen $\left(20500 \mathrm{~mm}^{2}\right)$ were put in contact with a $3 \% \mathrm{CaCl}_{2}$ solution and subjected to a 24 hours freeze/thaw cycle $\left(+20{ }^{\circ} \mathrm{C} /-20{ }^{\circ} \mathrm{C}\right)$ for 56 days. The result of the test is represented by the cumulative amount of scaled dry material collected after 7, 14, 28, 42 and 56 days from the surface of the specimens and it is expressed as $\mathrm{kg}$ of scaled material $/ \mathrm{m}^{2}$ of exposed concrete surface $\left(\mathrm{S}_{\mathrm{n}}\right)$. Results for Mix 1 and Mix 2 are shown in table 7.

Table 7: Resistance to scaling $\left(S_{n}\right)$ of concrete made with the new aggregates (Mix 1) compared with similar concrete with natural aggregates (Mix 2)

\begin{tabular}{|l|l|l|}
\hline Sample & u.m. & $\mathbf{S}_{\mathbf{n}}$ \\
\hline \hline Mix 1 & $\mathrm{kg} / \mathrm{m}^{2}$ & 0.17 \\
\hline Mix 2 & $\mathrm{kg} / \mathrm{m}^{2}$ & 0.29 \\
\hline
\end{tabular}

Results of Table 7 indicate that the behavior to freeze/thaw cycles of concrete produced with the new aggregates (Mix 1 ) is better compared to that of concrete produced with natural aggregates (Mix 2). In this case, the advantage of the 
better ITZ of concrete with the new aggregates seems overcome the disadvantage of the higher water absorption of the fine fraction.

\section{CONCLUSIONS}

The new technology transforms returned concrete into a granular material that can be used for the production of concrete, in substitution of natural aggregates. Concretes made with 100 per cent by weight of the new aggregates were developed in Japan; these concretes are characterized by good mechanical strength and durability, despite the lower density and the higher water absorption of the new aggregates compared with the original natural ones. These results can be ascribed to the improved microstructure of the concrete produced with the new aggregates, due to the refinement of the ITZ between the new aggregates and the cement paste.

The new technology is by far less impacting than the option of dumping of returned concrete and contribute to reduce the environmental impact of concrete production at the RMC plant. With the new technology, the double objective is accomplished: (a) preserving the natural resource by reducing the quarrying of aggregates and (b) eliminating the disposal of returned concrete to landfill. Beside environmental and social advantages, the new technology also reduces the costs of supplying of aggregates and of waste disposal. The proposed technology offers many advantages from environmental, social and economical point of view and represents a contribution in the field of concrete sustainability.

\section{ACKNOWLEDGEMENTS}

The authors want to acknowledge the following companies for their enthusiasm in applying the new technology and for the essential contribution to improve the process through the day by day practice: Shiraishi Corp. (Okayama), Sakuragaoka RMC (Kanagawa), Kaneko Concrete (Kanagawa), Hikawa Kyoritsu RMC (Shimane), Mitsuwa RMC (Yamagata), Morishima RMC (Shimane), Daito HIDA Concrete (Shizuoka plant), Nomura MaPro (Shizuoka), Kanazawa RMC (Ishikawa), Ito Shoten (Aichi)

\section{REFERENCES}

[1]. Obla, K., Kim, H. and Lobo, C., "Crushed returned concrete as aggregate for new concrete - Final report", RMC Research \& Education Foundation, 2007

[2]. Sato, Y., Oyamada, T. and Hanehara, S., "Applicability of sewage sludge ash (SSA) for paving material: A study on using SSA as filler for asphalt mixture and base course material", Proceedings of the Third International Conference on Sustainable Construction Materials and Technologies, Kyoto, Japan, 2013

[3]. Ye, G., van Breugel, K., Lura, P. and Mechtcherine, V., "Hardening process of binder paste and microstructure development" in Application of superabsorbent polymers (SAP) in concrete construction, Metchtcherine, V. and
Reinhardt, H. W. editors, Rilem State of the art reports, 2012, pp. 51-62

[4]. Ferrari, G., Miyamoto, M. and Ferrari A., "New sustainable technology for recycling returned concrete", Construction and Building Materials, 2014, in press, available on-line 1 February 2014

[5]. Yamaji, K., Osaka-Hyogo working group, "Manual for an efficient use of recycled aggregates - Study regarding the IWA system", Concrete Industry Association, 27/03/2014

[6]. Japan Society of Civil Engineers, "Standard Specifications for Concrete Structures - Materials and Construction 2007”, JSCE Guidelines for Concrete, 16, 2010

[7]. Scrivener, K.L., Crumbie, A.K. and Laugesen, P., "The Interfacial Transition Zone (ITZ) Between Cement Paste and Aggregate in Concrete", Interface Science, vol. 12, 2004, pp. 411-421

[8]. Poon, C.S., Shui, Z.H. and Lam, L., "Effect of microstructure of ITZ on compressive strength of concrete prepared with recycled aggregates", Construction and Building Materials, vol. 18, 2004, pp. 461-468

\section{BIOGRAPHIES}

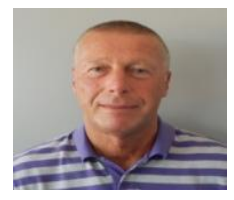

Giorgio Ferrari is Senior Researcher in Mapei. He is author of several scientific publications on concrete technology and environmental issues and he is author of international patents and two books.

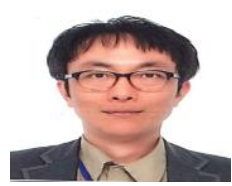

Mitsuya Miyamoto is CEO of Nagaoka Ready Mixed Concrete Company in Izuno-Kuni City, Shizuoka Prefecture, Japan and founding member of GNN, the Japanese Association of innovative RMC

Companies.

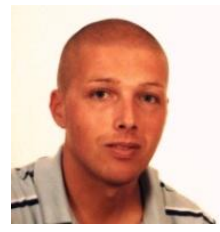

Alberto Ferrari is Product Manager of Nagaoka Ready Mixed Concrete Company in Izu-no-Kuni City, Shizuoka Prefecture, Japan. He is also the Secretary of GNN, the Japanese Association of innovative RMC Companies and contributor to Concrete Kogyo Shinbun.

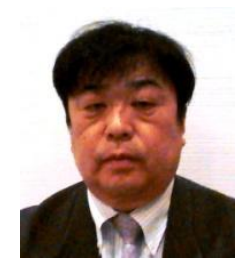

Kenichi Yoda is CEO of Yoda-Giichi Shouten and consultant for other RMC companies. He is founding member of GNN, the Japanese Association of innovative RMC Companies and former CEO and plant manager of Sakuragaoka RMC in Yokohama Area.

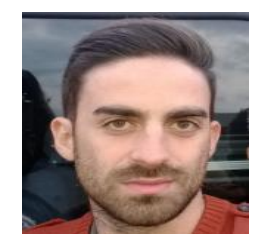

Michele Secco is Postdoctoral Fellow at the Department of Civil, Environmental and Architectural Engineering of the University of Padua. His research focuses on the characterization of inorganic binders and structural materials. 